\title{
The Relationship of Medical Sociology to Sociological Theory : Its Historical Root, Contributions and Contemporary Development
}

\author{
Victor Eyo Assi ${ }^{*}$ and Chima, Promise Akunna²
}

\begin{abstract}
${ }^{1 *}$ Department of Sociology, Faculty of Social Sciences, Ritman University Ikot Ekpene, Akwa Ibom State, Nigeria ${ }^{2}$ Federal polytechnic Ukana. Department of General Studies, Department of General Studies

E-mail: victorassi82@gmail.com; prommyy2k@gmail.com

*Corresponding author details: Victor Eyo Assi, victorassi82@gmail.com
\end{abstract}

\begin{abstract}
The nexus of this study was to examine the Relationship of Medical Sociology to Sociological Theory, its historical root, contributions and Contemporary Development. Medical sociology is a relatively new subdiscipline of the general field of sociology; today medical sociologists comprise one of the largest groups of sociologists in the world. Medical sociology began with a different orientation when compared to sociology's "core" fields. Unlike religion, law, politics, modes of economic production, and basic social processes, medicine was ignored by sociology's early theorists because it was not an institution shaping society. Medical sociology did not come of age until the late 1940s and early 1950s in an intellectual climate far different from sociology's traditional specialties with direct roots in nineteenth century social thought. Consequently, medical sociology evolved in circumstances dissimilar to those of most other sociological sub-disciplines. The notion that medical sociology is theoretical is wrong. Thus, this paper has provided a brief account of the history and variety of viewpoints in sociological theory that have been utilized within the field of medical sociology and has provided influential statements on the relationship between society and health. Beginning with Parsons and structural functionalism, medical sociology in reality has a rich theoretical tradition spanning almost 60 years and incorporating the work of both classical and contemporary theorists.
\end{abstract}

Keywords: medical sociology; sociological theory; historical root

\section{INTRODUCTION}

AN OVERVIEW OF MEDICAL SOCIOLOGY

Medical sociology is a relatively new sub-discipline of the general field of sociology; today medical sociologists comprise one of the largest groups of sociologists in the world. For example, the Medical Sociology Section is the largest speciality represented in both the British and German Sociological associations and the second largest among American sociologists. There are also European and Japanese Societies of Health and Medical Sociology. Since its inception in the years following World War II, medical sociology has not only acquired a large number of practitioners, but it has attracted significant funding for research, provided employment opportunities within and outside academia, and produced numerous books and a high volume of publications in specialized and general journals. (Cockerham, 1983)

Medical sociology began with a different orientation when compared to sociology's "core" fields (Ruderman 1981). Unlike religion, law, politics, modes of economic production, and basic social processes, medicine was ignored by sociology's early theorists because it was not an institution shaping society. Medical sociology did not come of age until the late 1940s and early 1950s in an intellectual climate far different from sociology's traditional specialties with direct roots in nineteenth century social thought. Consequently, medical sociology evolved in circumstances dissimilar to those of most other sociological sub-disciplines.
The principal difference is that medical sociology was expected by funding agencies and policymakers to be an applied field producing social knowledge that could be used in medical practice, public health campaigns, and health policy formulation. In contrast, other sociological specialties concerned with social stratification, groups, organizations, work, politics, and the like were grounded in theory and featured classical studies by major figures in the field.

Yet, the tremendous growth of medical sociology in both the United States and Europe in recent years most likely would not have been possible without the substantial financial support for applied studies provided by the respective governments. For example, in the United States, where medical sociology has reached its most extensive development, the emergence of the field was greatly stimulated by the expansion of the National Institutes of Health $(\mathrm{NIH})$ in the late 1940s. Particularly significant, according to August Hollingshead (1973), who participated in some of the early research programs, was the establishment of the National Institute of Mental Health (NIMH) that was instrumental in encouraging and funding joint social and medical projects. "It was through the impetus provided by this injection of money," noted Malcolm Johnson (1975), "that sociologists and medical men changed their affiliations and embraced the field of medical sociology. " When Alvin Gouldner (1970) discussed the social sciences as a well-financed government effort to help cope with the problems of industrial society and the 
welfare state in the West during the post-World War II era, the prototypical social science in this effort was medical sociology.

The same situation prevailed in Europe. A study conducted in the early 1980s concluded that government funding of research was the initial attraction to the field by the majority of respondents (Claus, 1982). Few were primarily affiliated with a university sociology department, and ties to the general discipline of sociology were depicted as weak. Work affiliation rather than professional prerequisites tended to determine identification as a medical sociologist, and the dominant employment pattern was to work in an applied role, typically research, in a medical institution. Furthermore, only about one-fourth of the respondents held a doctoral degree in sociology, and approximately one-third of those identifying themselves as medical sociologists had not received any formal training in medical sociology (defined as at least one course/seminar/ workshop in medical sociology during their education)

In the beginning of medical sociology's expansion, it is clear that many people in the field had tenuous roots in mainstream sociology and a work perspective oriented toward applied rather than theoretical interests (Cockerham 1983). This condition was reinforced by the tendency of increased levels of funding to correspond with increased demands for applied sociology that can be articulated into public policy by the sponsoring agency. The base for medical sociology in its formative years was in medical institutions, and many medical sociologists had little or no connection to the parent discipline.

This situation led Robert Straus (1957) to suggest that medical sociology had become divided into two areas: sociology in medicine and sociology of medicine. The sociologist in medicine is a sociologist who collaborates directly with physicians and other health personnel in studying the social factors that are relevant to a particular health problem. The work of the sociologist in medicine is intended to be directly applicable to patient care, and other practical uses in the area of health. Thus, sociology in medicine can be characterized as applied research and analysis primarily motivated by a medical problem rather than a sociological problem. Sociologists in medicine usually work in medical schools, nursing schools, public health schools, teaching hospitals, public health agencies, and other health organizations.

The sociology of medicine, on the other hand, has a different emphasis. It deals with such factors as the organization, role relationships, norms, values, and beliefs of medical practice as a form of human behavior. The emphasis is on the social processes that occur in the medical setting and how these contribute to our understanding of medical sociology in particular and to our understanding of social life in general. The sociology of medicine shares the same goals as all other areas of sociology and may consequently be characterized as research and analysis of the medical environment from a sociological perspective. Although some sociologists of medicine are employed in health institutions, they majorly work as professors in the sociology departments of universities and colleges.

However, the division of work in medical sociology into a sociology of medicine and sociology in medicine eventually created problems. Medical sociologists affiliated with departments of sociology in universities were in a stronger position to produce work that satisfied sociologists as good sociology. But sociologists in medical institutions had the advantage of participation in medicine as well as research opportunities unavailable to those outside medical practice. A certain amount of tension began to develop between the two groups over whose work was the most important. What happened to change this situation was a general evolution in medical sociology toward work that combined both applied and theoretical perspectives by medical sociologists in all settings. The division of the field as outlined by Straus lost its distinctiveness in the United States and never really developed in Western Europe. Most research in medical sociology today, regardless of whether it is in a sociology department in a university or in a medical institution, deals with practical problems.

Although the potential for dependence on medicine was a real possibility in the first years of medical sociology's development, the situation became less of a reality over time. Medical sociology did not evolve as a field providing research services in support of medicine. Rather, medical sociologists followed their own path and, in fact, became critics of medicine when the situation was warranted, as seen in some well-known studies dealing with the lack of access to health care by the poor (Kosa, Antonovsky, and Zola 1969), as well as medical mistakes (Millman,1977), failures (Bosk, 1979), and opposition to health reform (Starr, 1982). By the late 1990s, medical sociology had not only established an independent position relative to medicine, but it had also turned to mainstream sociology for its basic orientation. As Bernice Pescosolido and Jennie Kronenfeld (1995) point out, current thinking in medical sociology is often guided by concepts and theories associated with the parent discipline. And as the parent discipline adjusts its perspectives to the social changes accompanying the transition from the industrial age into postindustrial or late modern/postmodern society, further reconnections with medical sociology are predicted.

\section{MEDICAL SOCIOLOGY: THE BEGINNING}

The root of medical sociology can go back very much further than the period of rapid expansion that followed the end of the Second World War. The diversity in years ago in the development of medical sociology in Europe and in North America may therefore reflect the different historical and intellectual traditions that operate in the old and new world. Medical sociology emanates from Europe though America modified discipline.

Elizabeth Blackwell, the first woman to graduate from an American medical school, named a collection of essays on health topics Medical Sociology in 1902 and James Warbasse published a book of essays on medicine and society entitled Medical Sociology in 1909. In 1935, biologist and physician Lawrence Henderson, whose work strongly influenced Talcott Parsons, published a paper on "The Physician and Patient as a Social System" in the New England Journal of Medicine (Gerhardt, 1989). Interest in the field, largely on the part of physicians, was slowly growing but, as noted, medical sociology did not begin in earnest until after World War II. It was at this time that significant amounts of government funding for sociomedical research became available in the United States and Western Europe. Under the auspices of the National Institute of Mental Health, medical sociology's initial alliance in medicine was with psychiatry, a medical specialty that was undergoing a struggle of its own for professional status within its wider discipline. Prior to this time, sociologists had conducted important epidemiological research on mental disorders, creating a basis for cooperation between sociologists and psychiatrists. A particularly significant result of such cooperation was the publication in 1958 of Social Classed Mental Illness: A Community Study by Hollingshead 
(a sociologist) and Frederick Redlich (a psychiatrist). This landmark research produced important evidence that social factors were correlated with different types of mental disorders and the manner in which people received psychiatric care. This study attracted international attention and remains the best-known study in the world of the relationship between mental disorder and social class. The book played a key role in the debate during the 1960s leading to the establishment of community mental health centers in the United States.

The concern of America in medical sociology is to make a move from being a policy to applied and this caused them to go into researches, while the European medical sociology started as applied and now methodology is used in its findings. According to Pflanz and Siegrist Paper entitled, 'Basic assumption in medical sociology'. The term medical sociology has not been used in Germany before 1955, the matter itself has a long tradition in German medical thinking, the writings of Virchow and Salamon Neumann 1848 who belonged to the classics of medical sociology was of utmost importance. Another writer whose writing contributed to so much to the field of medical sociology is Meiller Lyer 1914, he wrote on the 'sociology of suffering'.

In British social history, it was accepted that social epidemiological research survey, research data was an important element in the development of reformist attitudes and subsequent legislative and administrative change. Social scientists in the United Kingdom and Europe became involved in the process of social reform. During the reform, Charles Booth and Seebohm Rowntree were concerned with the inevitable relationships between poverty; malnutrition and disease were the important force in persuading the establishment, to introduce a measure whose purpose was to improve the nutritional status of young people.

American reflected different developmental tradition. It is worthy of remembering that the United States of early 1950s enabled McCarthyism to develop and to attain a grip on social and political institution McCarthy was able to destroy the career of persons as diverse as obstetrician or gynecologist's by labeling them communists' and the medical sociologist of the time could not do anything because they were not in position of conducting policybased research except indirectly. As consequence, they were tempted to concentrate in both teaching and research, upon 'safer' academic issues in medical sociology. Medical sociology had to develop professional credibility as an academic discipline before it could even begin to address issues as those associated with social policy concerns. It was hypothesized that medical sociologist attached themselves to a highly prestigious profession, that of medicine, in an effort to develop credibility. It was after the sub-discipline had achieved credibility that they began to develop autonomously and to generate questions out of their own disciplinary perspective that were pertinent to broader social issues (Derek and Twaddle, 1976).

Monies from federal and private organizations also helped stimulate cooperation between sociologists and physicians in regard to socio-medical research on problems of physical health. In 1949 the Russell Sage Foundation funded a program to improve the utilization of social science research in medical practice. One result of this program was the publication in 1954 of Social Science in Medicine, co-authored by Leo Simmons (a sociologist) and Harold Wolff (a physician), which was intended to provide a framework for collaboration between social scientists and medical doctors. Other work sponsored by the Russell
Sage Foundation and appearing a few years later included Edward Suchman's Sociology and the Field of Public Health (1963). This book described how sociology could be applied to public health practice. When large-scale funding initially became available in the late 1940s, medical sociology was primarily oriented toward an applied approach.

\section{MEDICAL SOCIOLOGY AND SOCIOLOGICAL THEORY}

The link between medical sociology and sociological theory is crucial to the sub-discipline. Theory binds medical sociology to the larger discipline of sociology more extensively than any other aspect of the sociological enterprise. Theory is also what usually distinguishes research in medical sociology from socially oriented studies in allied fields, like public health and health services research. Whereas seminal sociological contributions in quantitative and qualitative data collection and analysis, along with many fundamental concepts of social behavior, have been adopted by multidisciplinary approaches in several fields, sociological theory allows medical sociology to remain unique among the health related social and behavioral sciences. This could be considered as a somewhat surprising statement because medical sociology has often been described in the past as atheoretical. It is true that much of the work in the field historically has been applied to practical problems rather than theoretical questions. That is, it was intended to help solve a clinical problem or policy issue, rather than develop theory or utilize it as a tool to enhance understanding.

Medical sociology was not established until after World War II when the American government provided extensive funding through the National Institutes of Health for joint sociological and medical research projects. The same situation prevailed in Western Europe, where, unlike in the United States, few medical sociologists were affiliated with university sociology faculties and connections to the general discipline of sociology were especially weak (Claus 1982; Cockerham 1983). It was primarily through the stimulus of the availability of government funding that sociologists and health professionals embraced medical sociology as a new sub-discipline. Funding agencies were not interested in theoretical work, but sponsored research that had some practical utility in postwar society as Western governments had come to realize that social factors were important for health. By the end of the twentieth century, however, this situation had changed significantly. Most research in medical sociology remains oriented toward practical problem solving, but the use of sociological theory in this endeavor is now widespread. There has been a general evolution of work in medical sociology that combines both applied and theoretical perspectives, with the utilization of theory becoming increasingly common as a framework for explaining or predicting health - related social behavior.

At the same time, medical sociology moved away from a state of dependence upon medicine for defining and guiding research agendas to a position of relative independence. Although the relationship between medical sociology and medicine has been important, it has not always been harmonious. Medical sociology tended to side with patients and call attention to instances of poor treatment, while some physicians have been contemptuous of medical sociologists in clinical settings. Yet medicine nurtured, funded, and sponsored medical sociology early in its development and continues to do so today. In fact, one could arguably state that medicine has supported medical sociology with funding and job positions to a much greater extent than sociology. 
It can also be claimed that the increased use of theory in medical sociology represents more of an effort on the part of medical sociologists to establish and reinforce links to the parent discipline than vice versa. In many ways, medicine has been a better ally of medical sociology than sociology.

While medical sociology is moving closer to sociology, it has generally removed itself from a subordinate position to medicine. There are four reasons for this development. First, the shift from acute to chronic diseases as the primary causes of death in contemporary societies has made medical sociology increasingly important to medicine. This is because of the key roles of social behavior and living conditions in the prevention, onset, and course of chronic disorders. Medical sociologists bring more expertise to the analysis of health - related social conditions than physicians, who typically receive little or no training in this area. Second, medical sociology has moved into a greater partnership with medicine as it has matured and fostered a significant body of research of literature, much of it relevant to clinical medicine and health policy. Third, success in research has promoted the professional status of medical sociologists, in relation to both medicine and sociology. And fourth, medical sociology has generally set its own research agenda, which includes medical practice and policy as an object of study. In the case of malpractice, failure to police incompetent practitioners, limited access to quality care for the poor, and placing professional interest ahead of the public 's interest, medical sociologists have been significant critics of medicine. In doing so, they have established themselves as objective professionals.

The movement of medical sociology toward greater connections with general sociology reflects the desire of a mature sub-discipline to expand its analytic capabilities and reinforce its potential. Changing social conditions associated with the transition in society from the postindustrial to the current late modern period requires all of sociology to account for altered circumstances and formulate new concepts. This situation suggests that not only is medical sociology connecting with general sociology, but that sociology is moving toward a closer affiliation with it given the considerations of health increasingly evident in the everyday social lives of people and medical sociology ' $s$ capacity for explaining it. Under the current conditions of social change, medical sociologists are making greater use of sociological theory because theory promotes the explanatory power of their empirical findings. This development has led some to suggest that medical sociology may indeed prove to be the "leading edge" in some areas of the development of contemporary theory (Turner, 1992). The extent to which this assertion will be fully realized is not yet certain, but it is clear that a considerable amount of theoretical work is taking place in medical sociology (Cockerham, 2007a). The remainder of this chapter will provide an overview of the field with respect to theory.

\section{CONTRIBUTION OF PIONEERS OF SOCIOLOGY TO MEDICAL SOCIOLOGY (PARSONS, DURKHEIM, AND STRUCTURAL FUNCTIONALISM)}

From 1946 to 1951, the new field of medical sociology was almost completely an applied area of research. Medical sociologists worked with psychiatrists and other physicians on government-funded projects to largely address medical problems; few were employed in university departments of sociology in the United States and they were generally absent from sociology faculties in Europe and Asia. However, a pivotal event occurred in 1951 that oriented medical sociology toward theoretical concerns and initiated the establishment of its academic credentials. This was the publication of Talcott Parsons' long anticipated book, The Social System, which established the author at the time as the dominant figure in American sociology (Ritzer 2008). Anything Parsons published attracted great attention because he was thought to be charting a course for all of sociology. This book, providing a structural-functionalist model of society, contained Parsons' concept of the sick role and was the first time a major sociological theorist included an analysis of the function of medicine in his view of society. Parsons (1951) was interested in the differing roles of professionals in capitalist and socialist societies and decided to include physicians and their relationship to their clients in his analysis because this topic was an area of long-standing interest and one in which he felt he had familiarity. Parsons himself had undergone training in psychoanalysis in the 1950s at the Boston Psychoanalytic Institute when he was on the faculty at Harvard University (Smelser, 1998).

This experience had grounded him in the theories of Sigmund Freud which became an important influence on his own work, along with the ideas of the classic sociological theorists Emile Durkheim and Max Weber. Parsons had completed his doctoral studies at Heidelberg University in Germany in the mid -1920s where he participated in the "Weber Circle" that continued to meet regularly to discuss sociology after Weber's death at the home of his widow, Marianne Weber. Parsons subsequently translated Weber's book on the Protestant Ethic and the Spirit of Capitalism (1958) into English, and reintroduced the work of both Weber and Durkheim to European sociologists after the disruption of their work during World War II. Freud's concepts of transference and counter-transference can be seen in the way Parsons drew analogies between the roles of parent-child and physician-patient important in his notion of the sick role. Freud's structure of the personality and theory of the unconscious are also apparent in his ideas on the motivation of sick persons to either recover or desire the "secondary gain" of privileges and exemption from normal social roles that accompany sick-role legitimation. Parsons likewise incorporates Durkheim's ideas on moral authority and Weber's analysis of religion into his discussion of the normative requirement to visit physicians when sick and the dominant position of the physician in the doctor-patient role relationship.

Parsons' concept of the sick role is a clear and straightforward statement of four basic propositions outlining the normative pattern of physician utilization by the sick and their respective social roles. Parsons not only constructed the first theoretical concept directly applicable to medical sociology, but by utilizing the work of Durkheim and Weber, he did so within the parameters of classical socio-logical theory. His formulation was recognized as "a penetrating and apt analysis of sickness from a distinctly sociological point of view" (Freidson 1970a), which indeed it was. Parsons also influenced the study of professions by using the medical profession as the model for professions based on expertise and a service orientation. Although extensive criticism was to subsequently lessen the acceptance of the Parsonian approach to theory, this outcome does not negate the significant influence Parsons initially had on promoting debate and research in medical sociology. Parsons, more so than any other sociologist of his time, made medical sociology academically respectable by providing it with its inaugural theoretical orientation.

However, structural functionalism, with its emphasis on value consensus, social order, stability, and functional 
processes at the macro-level of society, had a short-lived period as the leading theoretical paradigm in medical sociology. Robert Merton and his colleagues extended the structural-functionalist mode of analysis to the socialization of medical students in their book The Student Physician (1957), but other major works in medical sociology were not forthcoming. Structural functionalism itself was under assault by critics in the 1960s and early 1970s and lost considerable influence.

Durkheim (1950), who was generally responsible for the theory in sociology, emphasized the importance of macrolevel social processes, structures, norms, and values external to individuals that integrated them into the larger society and shaped their behavior. People were depicted as constrained in exercising free will by the social order. Durkheim's (1951) only work that had a direct application to medical sociology was his theory of suicide in which the act of taking one's life was deter-mined by the individual's ties to his or her community or society. This is seen in his typology of three major types of suicide: (1) egoistic (social detachment), (2) anomic (state of normlessness), and (3) altruistic (a normative demand for suicide). The merit of his concept is that it shows the capability of the larger society to create stressful situations where people are forced to respond to conditions not of their own choosing. Thus, Durkheim helps us not only to understand the social facets of suicide, but also to recognize that macro-level social events (like economic recessions) can affect health in a variety of ways through stress and that the effects of stress can be mitigated through social support (Cockerham 2010). Indirectly, Durkheim (1964) also influenced the study of health professions in noting the transition from mechanical to organic social solidarity, with its emphasis upon specialization, in the modern division of labor.

However, symbolic interactionist objected to the relegation of individuals to relatively passive roles in large social systems, while conflict theorists found structural functionalism inadequate in explaining the process of social change and the social functions of conflict. The theory's emphasis on equilibrium and consensus also seemed to favor maintenance of the status quo and support for dominant elites (Ritzer 2008), at a time (the 1960s) of widespread social protest against authority in the West. Structural functionalism in general and Parsons in particular suffered a serious fall in popularity, although Parsons' work enjoyed a mild resurgence in the 1990s (Callinicos 2007). Parsons' concept of the sick role, however, has remained a central theoretical proposition in medical sociology, despite challenges. It is still utilized as a basic ("ideal-type") explanation for physician-patient encounters in which the model of interaction is primarily that of guidance on the part of the physician and cooperation by the patient in clinics or patient care office settings.

\section{SYMBOLIC INTERACTION}

The first major theoretical perspective to challenge Parsons and structural-functionalist theory in medical sociology was symbolic interaction, based largely on the work of George Herbert Mead (1934) and Herbert Blumer (1969). Symbolic interaction maintained that social reality is constructed on a micro-level by individuals interacting with one another on the basis of shared symbolic meanings. Human beings were seen to possess the capacity to think, define situations, and construct their behavior on the basis of their definitions and interpretations. "It is the position of symbolic interaction," states Blumer (1969), "that the social action of the actor is constructed by him [or her]; it is not a mere release of activity brought about by the play of initiating factors on his [or her] organization."
Social life was therefore produced by interacting agents choosing their own behavior and acting accordingly, not by large-scale social processes and structures channeling behavior down option-less pathways. Symbolic interaction had not only its particular (micro-level) orientation toward theory construction, but also its own qualitative research methodologies of participant observation that focused on small group interaction in natural social settings. A related approach was ethnomethodology, which featured description of taken-for-granted meanings in natural settings, rather than analysis.

The major figures in early medical sociology working in the symbolic interactionist tradition were Anselm Strauss and Erving Goffman. Strauss joined with Howard Becker and others in their now classic study of medical school socialization, Boys in White (Becker et al. 1961). Strauss made his own contributions to theory and methods in a number of areas, including seminal work on the social process of death and dying (Glaser and Strauss 1965, 1968); observation of the "negotiated order" of hospital routine featuring a minimum of "hard and fast" regulations and a maximum of "innovation and improvisation" in patient care, especially in emergency treatment (Strauss et al. 1963); and formulation of grounded theory methodology featuring the development of hypotheses from data after their collection, rather than before (Glaser and Strauss 1967)

Goffman, who became a major theorist in sociology generally, began his research career in medical sociology by using participant observation to study the life of mental hospital patients. His classic work in this area, Asylums (1961), presented the concept of "total institutions" that emerged as an important socio-logical statement on the social situation of people confined by institutions. His observations also led to the development of his notions of impression management and the dramaturgical perspective in sociology that views "life as a theatre" and "people as actors on a stage," as well as his concept of stigma (Goffman 1959, 1967).

With the introduction of symbolic interactionist research into an area previously dominated by structural functionalism, medical sociology became an arena of debate between two of sociology's major theoretical schools. By the mid-1960s, symbolic interaction came to dominate a significant portion of the literature in the field. One feature of this domination was the numerous studies conducted in reference to labeling theory, a variant of symbolic interaction, and the controversy it provoked. Labeling theory held that deviant behavior is not a quality of the act a person commits but rather is a consequence of the definition applied to that act by others (Becker 1973). That is, whether or not an act is considered deviant depends upon how other people react to it. Although labeling theory pertained to deviance generally, the primary center of argument was focused on the mental patient experience, with Thomas Scheff (1999) the principal proponent of the labeling approach. Labeling theory was also employed in studies of the medical profession as seen in Eliot Freidson's (1970b) alternative concept of the sick role.

By the 1980s, however, symbolic interaction entered a period of decline in medical sociology. Many of its adherents had been "rebels" intentionally subverting the dominant paradigm of structural functionalism and giving voices to women and marginal social groups like mental patients, the physically handicapped, and the aged and their caratakers by entering their social world and observing it. 
Yet, as Norman Denzin (1991) points out, between 1981 and 1990 , the canonical texts in the field had shifted from Mead to Blumer and Blumer himself was under attack on several methodological and substantive issues - but most importantly for not advancing the field to meet his own early criticisms; moreover, practitioners of the perspective were getting older ("the graying of interactionism"), the number of students espousing interactionism was decreasing, and the old enemy (structural functionalism) had been largely vanquished. Elsewhere, in Great Britain, where interactionism had been the dominant theoretical perspective in medical sociology as seen in the majority of published studies (Annandale 1998), a related theoretical perspective - social constructionism - is now the leading theory (Nettleton 2006; Seale 2008).

Unfortunately, symbolic interaction had taken on the image of a "fixed doctrine" and, except for Mead's (1934) concept of the "generalized other," was unable to satisfactorily link small group processes with social phenomena reflecting the behavioural influences of the larger society. It was particularly unable to account for interaction between institutions or societal-level processes that affect each other, not just individuals or groups. In addition, labeling theory, despite its merits in accounting for the powerful behavioral effects of "labels" placed on people, had not been able to explain the causes of deviance (other than the reaction of the social audience), nor whether deviants themselves share common characteristics like poverty, stress, family, or class background.

But it would be a mistake to relegate symbolic interaction to history, as participant observation remains the primary form of qualitative research in medical sociology. Participant observation and ethnomethodology are still the best methods for recording social behavior from the personal standpoint of those being studied and the settings within which they lead their usual lives. Moreover, the observed patterns of behavior and first-person accounts of social situations bring a sense of "real life" to studies that quantitative research is unable to capture. While symbolic interaction theory has not moved far beyond the original concepts of Mead and Blumer, it persists as an important theoretical approach to the study and explanation of social behavior among small groups of people interacting in ways that are relevant for health.

One area of research in medical sociology helping to revive symbolic interaction is the sociology of emotions, a topic neglected in the past. Research in this field seeks to understand the link between social factors and emotions, since emotions are expressed either in response to social relationships or situations or both. Symbolic interactionism fills in the analytic gap between organic or biological approaches to the study of emotions and sociological approaches like social constructionism that ignores biological processes and focuses more or less exclusively on the social and cultural components of emotions (Williams and Bendelow 1996). Interaction between people plays perhaps the major role in the activation and expression of emotions and analyzing interpersonal relations is a strength of symbolic interaction. Emotions, as Simon Williams (1998) points out, are existentially embodied states that also connect "personal troubles" to social structures in ways that affect health and shape patterns of disease. Williams finds, for example, that feelings of stress, helplessness, depression, sense of coherence, insecurity, and lack of control have consistently been shown to be associated with increased levels of mortality and morbidity.

\section{CONFLICT THEORY}

Conflict theory, with its roots in the work of Karl Marx and Max Weber, joined symbolic interaction in significantly reducing the influence of structural functional-ism, but has yet to establish a major foothold in medical sociology. Conflict theory is based on the assumption that society is composed of various groups struggling for advantage that inequality is a basic feature of social life, and conflict is the major cause of social change. Marx's perspective in conflict theory is seen in the rejection of the view expressed by structural functionalism that society is held together by shared norms and values. Conflict theory claims that true consensus does not exist; rather, society's norms and values are those of the dominant elite and imposed by them on the less privileged to maintain their advantaged position. Weber adds, however, that social inequality is not based on just money, property, and relationships to the means of production, but also on status and political influence. Since all social systems contain such inequality, conflict inevitably results and conflict, in turn, is responsible for social change.

Whereas the Marxian-oriented features of conflict theory have emphasized class struggle, other theorists have moved toward emphasizing conflicts that occur between interest groups and the unequal distribution of political power (Dahrendorf 1959). According to Turner (1988), modern societies are best understood as having a conflict between the principles of democratic politics (emphasizing equality and universal rights) and the organization of their economic systems (involving the production, exchange, and consumption of goods and services, about which there is considerable inequality). Therefore, while people have political equality, they lack social equality. This unresolved contradiction is relatively permanent and a major source of conflict. Ideologies of fairness are constantly challenged by the realities of inequalities, and they influence governments to try to resolve the situation through politics and welfare benefits.

This situation represents one of conflict theory's most important assets for medical sociology; namely, the capacity to explain the politics associated with health reform. Conflict theory allows us to chart the maneuvers of various entities, like the medical profession, insurance companies, drug companies, the business community, and the public, as they struggle to acquire, protect, or expand their interests against existing government regulations and programs and those under consideration. Other conflict approaches are connected more directly to classical Marxism by relying on class struggle to explain health policy outcomes (Navarro 1994) and the disadvantages of the lower and working classes in capitalist medical systems where the emphasis is on profit (McKinlay 1984; Waitzkin 1983). While a major focus of conflict theory in medical sociology is on the role of competing interests in health care delivery and policy, other interests concern the sources of illness and disability in work environments, working-class health, differences in health lifestyles, and capitalist ideologies in the physician-patient relationship (Blane 1987; McKinlay 1984; Navarro 1986; Waitzkin 1983, 1989, 1991).

However, there are inherent limitations in the use of conflict theory in medical sociology. While some health situations are affected by conflict related conditions, others are not. People may maintain their health or become sick and these outcomes can have little or nothing to do with conflict, politics, interest group competition, class struggles, and the like. Moreover, Marxism began losing influence from the late 1970s onward. As Alex Callinicos (2007) points out, political events sank Marxist theory in the universities. First, French scholars turned their back on Marxism as a "theory of domination" 
in response to Soviet labor camps, the Cold War, and the crackdown on Solidarity in Poland in 1981, followed by similar reactions elsewhere in Europe and Latin America. "The process of retreat was slower in the English-speaking world," states Callinicos (2007), "but by the beginning of the 1990s, under the impact of postmodernism and the collapse of 'existing socialism' in Eastern Europe and the Soviet Union, Marx was a dead dog for most intellectuals there as well." As a political doctrine, Marxism-Leninism also failed to construct healthy social conditions and an adequate health care delivery system in the former Soviet Union and the East European socialist countries that experimented with it (Cockerham 1997, 1999, 2000, 2007b). Most of these countries experienced a 30-year decline (1965-95) in male life expectancy and for some - Belarus, Kazakhstan, Russia, and Ukraine - the health crisis is still continuing (Cockerham 2007b; Cockerham et al. 2006a, 2006b). The epicenter of the downturn in life expectancy was in Russia where male longevity fell 5.2 years between 1965 and 2005 and female life expectancy rose only 0.3 years. The theoretical and practical failure of Marxism to produce healthy societies substantially undermines the utility of Marxist-based theories in medical sociology (Cockerham 2007a). The greatest potential of conflict theory for medical sociology thus lies in its non-Marxist aspects, as interest-group competition in welfare states proves more relevant for health concerns than Marxist notions of class struggle.

\section{MAX WEBER}

None of the classical theorists - Comte, Spencer, Simmel, Marx, Durkheim, and Weber - concerned themselves with medical sociology. Weber, however, has had the greatest direct influence on the field. His most important contributions are associated with his concepts of formal rationality and lifestyles. Weber (1978) distinguished between two major types of rationality: formal and substantive. Formal rationality is the purposeful calculation of the most efficient means and procedures to realize goals, while substantive rationality is the realization of values and ideals based on tradition, custom, piety, or personal devotion. Weber described how, in Western society, formal rationality became dominant over its substantive counterpart as people sought to achieve specific ends by employing the most efficient means and, in the process, tended to disregard substantive rationality because it was often cumbersome, time-consuming, inefficient, and stifled progress. This form of rationality led to the rise of the West and the spread of capitalism. It is also linked to the development of scientific medicine and modern social structure through bureaucratic forms of authority and social organization that includes hospitals (Hillier 1987). The rational goal-oriented action that takes place in hospitals tends to be a flexible form of social order based on the requirements of patient care, rather than the rigid organization portrayed in Weber's concept of bureaucracy (Strauss et al. 1963). But his perspective on bureaucracy nevertheless captures the manner in which authority and control are exercised hierarchically and the importance of organizational goals in hospital work (Hillier 1987).

Weber's notion of formal rationality has likewise been applied to the "deprofessionalization" of physicians. Deprofessionalization means a decline in power resulting in a decline in the degree which a profession maintains its professional characteristics. Freidson's (1970a, 1970b) seminal work on the medical profession in the 1970s had captured American medicine's professional dominance in its relations with patients and external organizations. Medicine was the model of professionalism, with physicians having absolute authority over their work and ranked at or near the top of society in status. However, Ritzer and Walczak (1988) noted the loss of absolute authority by physicians as their treatment decisions came under increasing scrutiny in the late twentieth century by patients, health care organizations, insurance companies, and government agencies.

Ritzer and Walczak found that government policies emphasizing greater control over health care costs and the rise of the profit motive in medicine identified a trend in medical practice away from substantive rationality (stressing ideals like serving the patient) to formal rationality (stressing rules, regulations, and efficiency). Government and insurance company oversight in reviewing and approving patient care decisions, and the rise of private health care business corporations, decreased the autonomy of medical doctors by hiring them as employees and controlling their work. This, joined with greater consumerism on the part of patients, significantly reduced the professional power and status of physicians. Thus, the "golden age" of medical power and prestige ended, as medicine's efforts to avoid regulation left open an unregulated medical market that invited corporate control and public demands.

\section{RECENT AND CONTEMPORARY HAPPENINGS IN MEDICAL SOCIOLOGY}

In recent times there is a degree of convergence in medical sociology of America and Europe. A much more critical attitude is emerging towards the healthcare professions, partly as a result of the rising costs of healthcare in all modern western industrialized countries. Most countries are making effort to ration healthcare. Of the countries under review United Kingdom has been most successful in keeping expenditure in terms of health services.

Increased concern over the rising healthcare costs has also attracted other academic disciplines to the general healthcare field. Courses in hospital and health services administration are developing throughout the western world with a view to improving health services administration, thereby attempting to reduce the escalating cost of expenditures (Derek G. Gill and Andrew Twaddle). Medical sociology is an important substantive area within the general field of sociology that understands the evolution and development of the professionalization of medicine. It appreciates the traditional and the modern forms of health care delivery system.

In the last decade, medical sociology has been fast growing. An increasing recognition of the importance of social factors associated with various illness states has ensured medical sociology a continuing place in teaching and research. And as an expertise supplementary to existing medical knowledge the status of medical sociology is assured, yet interestingly, as a branch of sociology, its position is ambiguous (Margaret Reid, 1976).

Over the years, sociology of medicine has traversed many areas and thus embraces some areas of social medicine especially the aspect of social epidemiology and an aspect of hospital organization and care. In Nigeria, the development has brought some scholars into the discipline. Two main medical system has been identified: the orthodox and the traditional medicine. The orthodox medicine covers the primary healthcare centres, hospitals and the teaching hospitals while traditional medicine or healing is considered most appropriate for prolonged illnesses which are diagnosed to be of pre-natural origins (Oke, 1995). Their integration has been a major contemporary challenge. 


\section{SUMMARY AND CONCLUSION}

Theory binds medical sociology to the larger discipline of sociology more extensively than any other aspect of sociological work. Theory is also what usually distinguishes research in medical sociology from sociallyoriented studies in allied fields, like public health and health services research and allows it to remain unique among the health-related social and behavioral sciences. This could be considered a somewhat surprising statement because medical sociology has often been described in the past as atheoretical. It is true that much of the work in the field historically has been applied to practical problems rather than theoretical questions, but this situation has changed dramatically. The use of sociological theory is now widespread. There has been a general evolution of work in medical sociology that combines both applied and theoretical perspectives, with the utilization of theory becoming increasingly common as a framework for explaining or predicting health-related social behavior.

Medical sociology has been a new area of specialization in the field of sociology within the last decade, the area of medical sociology has been fast growing in term of development theoretically and in researches. The contributors in the field of medical sociology were not of the medical profession until recent considering changes within the medical sociology; one must also take into account the growing importance and professional strength of health workers in the field.

The notion that medical sociology is atheoretical is wrong. This paper has provided a brief account of the history and variety of viewpoints in sociological theory that have been utilized within the field and provided influential statements on the relationship between society and health. Beginning with Parsons and structural functionalism, medical sociology in reality has a rich theoretical tradition spanning almost 60 years and incorporating the work of both classical and contemporary theorists. Debates in general sociology, such as those involving the opposition of symbolic interactionist and conflict theorists to structural functionalism and the current agency versus structure dispute, became points of theoretical contention in medical sociology as well. During the latter part of the twentieth century, structural theories like structural functionalism were largely abandoned in favor of agency oriented theories like symbolic interaction, labeling theory, and the agency side of social constructionism.

However, improved statistical techniques to measure the effects of structure - such as hierarchical linear modeling forecast a paradigm shift back to greater considerations of structure and structural approaches to theory (Cockerham 2007a). Although it is too early to determine the ultimate direction of theory in medical sociology this century with exact precision, these improved statistical procedures should provide a more comprehensive approach to research with theory guiding and adjusting to this capability. Already the theoretical basis for work in the field is extensive and its potential explanatory power is likely to increase. Medical sociology has become a theoretical sub-discipline.

Many researches have been carried out in the epidemiological area of the discipline. Much has been written about sociology and medicine, though there has been debate over the definition of medical sociology and the nature of its contribution to medicine and sociology. There has been some contribution of sociological theory to the study of some phenomena in the sub-discipline though not much has been done. Medical pervade our everyday language and life, hence decision about future work is of utmost importance to take the discipline to a greater height that will be attested by both sociologist and the medical professionals.

\section{REFERENCES}

[1] Annandale, Ellen. (1998). The Sociology of Health and Medicine: A Critical Introduction. Cambridge: Polity Press.

[2] Becker, H. S., Blanche G., Everett H., and Strauss, A. (1961). Boys in White: Student Culture in Medical School. Chicago: University of Chicago Press.

[3] Blumer, H. (1969). Symbolic Interactionism. Englewood Cliffs, NJ: Prentice-Hall. Bourdieu, Pierre. 1984. Distinction: A Social Critique of the Judgement of Taste. London: Routledge.

[4] Bosk, C. (1979). Forgive and Remember: Managing Medical Failure. Chicago: University of Chicago Press.

[5] Callinicos, Alex. (2007). Social Theory: A Historical Introduction, 2nd edition. Cambridge: Polity.

[6] Claus, E. (1982). The Growth of a Sociological Discipline: On the Development of Medical Sociology in Europe. Vol. I. Leuven: Sociological Research Institute, Katholieke Universiteit Leuven.

[7] Cockerham, W. C. (1983). "The State of Medical Sociology in the United States, Great Britain, West Germany, and Austria." Social Science and Medicine 17:1513-1527.

[8] Cockerham, W. C. (2007a). Social Causes of Health and Disease. Cambridge: Polity Press.

[9] Cockerham, W. C. (2007b). "Health Lifestyles and the Absence of the Russian Middle Class." Sociology of Health and Illness 29: 457-73.

[10] Cockerham, William C. 2010. Medical Sociology, 11th edition. Upper Saddle River, NJ : Pearson PrenticeHall.

[11] Dahrendorf, R.(1959). Class and Conflict in Industrial Society. Stanford, CA: Stanford University Press .

[12] Denzin, N. K. 1991. Symbolic Interactionism and Cultural Studies . Oxford: Blackwell.

[13] Derek, G. and Twaddle, A. (1976). 'Medical Sociology': What's in a name: Published in University of Missoun Press.

[14] Durkheim, E. 1964 (1893). The Division of Labor in Society. New York: Free Press.

[15] Durkheim, Emile. 1950 (1895). The Rules of Sociological Method. New York : Free Press.

[16] Durkheim, Emile. 1951 (1897). Suicide: A Study in Sociology. Glencoe, IL: Free Press

[17] Freidson, Eliot. (1970a). Profession of Medicine: A Study of the Sociology of Applied Knowledge. New York: Dodd \& Mead.

[18] Freidson, Eliot. 1970b. Professional Dominance. Chicago: Aldine. 
[19] Gerhardt, U. (1989). Ideas about Illness: An Intellectual and Political History of Medical Sociology. London: Macmillan.

[20] Glaser, B. G. and Strauss. A. M. (1965). Awareness of Dying. Chicago: Aldine.

[21] Glaser, B. G. and Strauss, A. M. (1967). The Discovery of Grounded Theory. Chicago: Aldine.

[22] Glaser, B. G. and Strauss, A. M. (1968). Time for Dying. Chicago: Aldine.

[23] Glassner, Barry. (1989). "Fitness and the Postmodern Self." Journal of Health and Social Behavior 30: 180-91.

[24] Goffman, E. (1959). The Presentation of Self in Everyday Life. New York: Anchor.

[25] Goffman, E. (1961). Asylums. Anchor.

[26] Goffman, Erving. 1967. Stigma: Notes on the Management of Spoiled Identity. Engelwood Cliffs, NJ: Prentice-Hall.

[27] Gouldner, A. W. (1970). The Coming Crisis of Western Sociology. New York: Basic Books.

[28] Hillier, S. (1987). "Rationalism, Bureaucracy, and the Organization of Health Services: Max Weber 's Contribution to Understanding Modern Health Care Systems." Pp. 194- 220 in G. Scambler (ed.), Sociological Theory and Medical Sociology. London: Tavistock.

[29] Hollingshead, A. B.( 1973). "Medical Sociology: A Brief Review." Milbank Memorial Fund Quarterly 51:531-542.

[30] Light, D. W., and Schuller. A. (1986). Political Values and Health Care: The German Experience. Cambridge: MIT Press.

[31] Johnson, M. (1975). "Medical Sociology and Sociological Theory." Social Science and Medicine 9:227-232.

[32] Kosa, J; Antonosvsky, A and Zola, I. K. (eds.). (1969). Poverty and Health. Cambridge, MA: Harvard University Press.

[33] McKinlay, John (ed.). 1984. Issues in the Political Economy of Health Care . London: Tavistock.

[34] Millman, M. (1977). The Unkindest Cut. William Morrow: New York.

[35] Navarro, Vicente. (1994). The Politics of Health Policy. Oxford: Blackwell.

[36] Nettleton, Sarah. (2006). The Sociology of Health and Illness, 2nd edition. Cambridge: Polity Press.

[37] Oke, E. (1991). "Anthropology in Medical Curriculum” A PAPER Presented at Nigerian Association of College of Medicine Workshop on the Integration of Social Sciences into Undergraduate medical Training in Nigeria.
[38] Pescosolido, B. A., and Jennie J. K. (1995). "Health, Illness, and Healing in an Uncertain Era: Challenges from and for Medical Sociology." Journal of Health and Social Behavior (Extra issue):5-33.

[39] Reid, M. (1976). The Development of Medical Sociology in Britain. Discussion Papers in Social Research No.13, University of Glasgoco.

[40] Ritzer, G. (2008). Modern Sociological Theory, 7th edition. New York: McGraw-Hill.

[41] Ritzer, G and David W. (1988). "Rationalization and the Deprofessionalization of Physicians." Social Forces 67: 1-22.

[42] Ruderman, F. (1981). "What Is Medical Sociology?" Journal of the American Medical Association 245:927-929.

[43] Smelser, Neil J. (1998). The Social Edges of Psychoanalysis. Berkeley: University of California Press.

[44] Starr, P. (1982). The Social Transformation of American Medicine. New York: Basic Books.

[45] Straus, R. (1957). "The Nature and Status of Medical Sociology." American Sociological Review 22:200-204.

[46] Turner, Bryan S. (1992). Regulating Bodies. London: Routledge.

[47] Williams, S. J. and Gillian B. (1996). "Emotions, Health and Illness: The 'Missing Link' in Medical Sociology." Pp. 25-53 in V. James and J. Gabe (eds.), Health and the Sociology of Emotions. Oxford: Blackwell. 